Classification

Physics Abstracts

$07.80-82.80$

\title{
A critical evaluation of the results of the 1992 round robin Microanalysis Test (EDXS and PEELS) performed by the Ile de France TEM network
}

\author{
Réseau Francilien de Microscopie Electronique en Transmission( $\left.{ }^{\star}\right)$
}

\author{
Contact : Danièle Bouchet
}

Laboratoire de Physique des Solides, Bât. 510, Université Paris-Sud, 91405 Orsay, France

(Received July 15, 1993; accepted September 22, 1993)

\begin{abstract}
Résumé. - Le Réseau Francilien d e Microscopie Electronique en Transmission a initié en 1992 un Atelier de Recherche intitulé "Analyse Chimique". Le but de cet atelier était d'organiser des tests tournants dans le but de développer les échanges scientifiques et techniques entre les microscopistes de la région et d'améliorer ainsi le savoir faire général. Le sujet du premier test était : "Analyse quantitative de l'olivine". Parmi la vingtaine de laboratoires équipés en microscopes que comptent Paris et sa région, quinze ont participé à cette expérience nouvelle. Cet article expose et analyse les résultats obtenus et tente d'identifier et de discuter les sources de déviation entre les différentes mesures.
\end{abstract}

\begin{abstract}
The "Réseau Francilien de Microscopie Electronique en Transmission" has run in 1992 a regional research workshop entitled "Chemical Microanalysis". The purpose of this workshop was to organise round robin tests in order to develop scientifical and theoretical exchanges within the electron microscopists community. The subject of the first test was: "Quantitative analysis of an homogeneous olivine". Among the 20 microscopes of the Paris region, 15 have participated to this experiment. This present report analyses the obtained results and tries to critically identify and discuss the sources of deviation between measurements in order to improve the general know-how.
\end{abstract}

$\left.{ }^{\star}{ }^{\star}\right)$ D. Bouchet, C. Colliex (LPS/CNRS, UPS Orsay); J. Ingrin (Géophysique et Géodynamique Interne, CNRS, UPS Orsay; D. Imhoff, C. Marhic (LPM-CNRS Meudon); G. Hug (LEM-ONERA-CNRS Châtillon); C. Servant, C. Haut (LMS-CNRS-UPS Orsay); P. Dascotte, E. Merlen (IFP Rueil-Malmaison); P. Galtier (Thomson-CSF Orsay); M.C. Sainte-Catherine, J.L. Derep (CREA-ETCA Arcueil); J. Devaud, J.L. Pastol (CECM-CNRS Vitry); R. Molins (EMP Paris); Y. Wang (LMC Paris VI); P. Boivin (ONERA Châtillon) Y. Montardi (Rhône Poulenc-CRA Aubervilliers); L. Boulanger (CEA Saclay). 


\section{Introduction.}

The "Réseau Francilien de Microscopie Electronique en Transmission" (Ile-de-France - TEM Network), created in 1987, gathers about 20 research laboratories using this technique in the "Ile-de-France" region around Paris. The main purpose of the creation of the Réseau was to promote and stimulate scientifical and technical exchanges between the scientists in order to confront and improve their ability, and to develop the field of application of transmission electron microscopy. Within this general content, research workshops have been organized. Different laboratories work together on a same problem, for example through a round robin test. In this kind of experimental test, a well-defined specimen circulates among the participating laboratories which all perform the same experiment. The results are then gathered, analysed, synthetised and finally discussed between all participants. This paper reports the activity of the "Chemical Analysis Research Workshop". The simple and exploratory subject of the first round robin test, in 1992, was "Quantitative analysis of an olivine thin foil by X-ray EDS and EELS".

TEM based X-ray EDS and EELS analytical systems are now widely spread in a number of laboratories. However, many problems, which can be sometimes relatively complex, appear when one wants to perform reliable quantitative analysis. The present test was therefore mostly devoted to point out these problems, to rise the questions and to generate a common approach within the group of users in order to define common and rigorous analysis procedures. This paper shows how an assembly of microscopists, coming from various horizons, non necessarily specialists or theoricists of microanalysis, can use the potential wealth of an interdisciplinary approach to improve their ability by selfteaching.

\section{Test procedure.}

2.1 ChARACTERISTICS OF THE OlIVINE SAMPLE. - The choice of the specimen has been determined by several criteria:

- The natural mineral San Carlos olivine, $(\mathrm{Mg}, \mathrm{Fe})_{2} \mathrm{SiO}_{4}$, has been extensively studied by the mineralogical community and is particularly known for its homogeneity. The reference composition has been obtained by preliminary microprobe analysis and is expressed as (average of ten analysis under $15 \mathrm{kV}, 5 \mathrm{~mA}$ ):

$$
\begin{gathered}
\left.\mathrm{Mg}_{1.79 \pm 0.02} \mathrm{Fe}_{0.200 \pm 0.007} \mathrm{Ni}_{0.008 \pm 0.001} \mathrm{Mn}_{0.003 \pm 0.001} \mathrm{Ca}_{0.002 \pm 0.001}\right) \\
\mathrm{Si}_{1.00 \pm 0.01} \mathrm{O}_{4}
\end{gathered}
$$

where the uncertainties are the maximum observed deviations; oxygen is deduced by stoichiometry.

-The second reason for the choice of this olivine is the presence of both heavy ( $\mathrm{Fe}, \mathrm{Ni}, \mathrm{Mn}$ ) and light $(\mathrm{O}, \mathrm{Mg})$ elements. Furthermore, minor concentration elements $(\mathrm{Ni}, \mathrm{Mn}$ and $\mathrm{Ca})$ are also well characterized and exhibit a suitable distributed range of concentrations in order to test the detection efficiency of the microanalysis.

Three TEM samples have been prepared by ion thinning with a Gatan ion-mil $(5 \mathrm{kV}, 0.5 \mathrm{~mA}$ per gun with an incident angle of $15^{\circ}$ ) and glued between two copper disks. Finally, the three foils have been simultaneously carbon coated on one side under high vacuum conditions. These foils satisfy the last but not the least suitable criterion for such a round robin test: there are strong enough to survive numerous travels and multiple handlings.

2.2 TEST CONDITIONS. - The three thin foils have been circulated so that each laboratory could keep one specimen for a period of about one week. Information was provided about the homo- 
geneity of the sample, the rough structural formula $(\mathrm{Mg}, \mathrm{Fe})_{2} \mathrm{SiO}_{4}$ of the monocrystal and the conditions of the specimen preparation. The participants were asked to perform analysis in two modes:

- a standard mode with a probe diameter of about $100 \mathrm{~nm}$,

- a nanoprobe mode with a probe diameter of about $5 \mathrm{~nm}$.

They were asked to obtain the quantitative analysis of major elements and to detect minor elements, eventually to quantify them. Details on the analytical equipment and the quantification process have been provided by each laboratory together with the results.

After compilation, analysis and synthesis of the results by the animation group, all encountered problems were discussed during a meeting of all the participants. A final synthesis and the prospects have been presented at the $3^{\text {rd }}$ Réseau Conference held in CECM-CNRS Vitry (Dec. $\left.11^{\text {th }}, 1992\right)$.

Table I. - X-ray analyses results and detector characteristics. Standard text corresponds to the results of standard mode analysis and italic text shows the results of nanoprobe analysis. The $k$-factors have been provided by the company $\left(k_{\text {comp }}\right)$ or have been calibrated from standard specimens $\left(k_{\text {calib }}\right)$. The concentration values are expressed in atomic fractions.

\begin{tabular}{|c|c|c|c|c|c|c|c|c|c|c|c|}
\hline Lab. & $\mathbf{k V}$ & $\begin{array}{l}\text { Window } \\
\text { area mm }{ }^{2}, \\
\text { Take-off }\end{array}$ & \begin{tabular}{l|} 
Absorption \\
correction \\
(thickness)
\end{tabular} & $\begin{array}{c}\mathrm{K}- \\
\text { factors }\end{array}$ & $\mathbf{M g}$ & $\mathrm{Fe}$ & $\mathbf{S i}$ & 0 & $\mathrm{Ni}$ & $\mathbf{M n}$ & $\mathrm{Ca}$ \\
\hline 1 & 200 & $30,20^{\circ}$ & $100 \mathrm{~nm}$ & $\mathbf{K}_{\text {comp }}$ & $\begin{array}{l}1.70 \\
1.59 \\
\end{array}$ & $\begin{array}{l}0.32 \\
0.29 \\
\end{array}$ & $\begin{array}{l}0.99 \\
1.00 \\
\end{array}$ & $\begin{array}{l}3.98 \\
4.08 \\
\end{array}$ & $\begin{array}{l}0.01 \\
0.01 \\
\end{array}$ & $\begin{array}{l}0.005 \\
0.005 \\
\end{array}$ & \\
\hline 2 & 300 & $30,15^{\circ}$ & & $\mathbf{K}_{\text {comp }}$ & $\begin{array}{l}1.41 \\
1.44 \\
\end{array}$ & $\begin{array}{l}0.42 \\
0.31 \\
\end{array}$ & $\begin{array}{l}1.14 \\
1.25 \\
\end{array}$ & $\begin{array}{l}4 \\
4 \\
\end{array}$ & $\begin{array}{l}\text { traces } \\
\text { traces }\end{array}$ & traces & \\
\hline 3 & 100 & $10,10^{\circ}$ & & $\mathrm{K}_{\text {theor}}$ ? & $\begin{array}{l}1.81 \\
1.47\end{array}$ & $\begin{array}{l}0.21 \\
0.23\end{array}$ & $\begin{array}{l}0.98 \\
1.30 \\
\end{array}$ & $\begin{array}{l}4 \\
4 \\
\end{array}$ & traces & & \\
\hline 4 & 200 & $10,70^{\circ}$ & & $\mathbf{K}_{\text {calib }}$ & $\begin{array}{l}1.79 \\
1.76 \\
\end{array}$ & $\begin{array}{l}0.21 \\
0.21 \\
\end{array}$ & $\begin{array}{l}1.00 \\
1.02 \\
\end{array}$ & $\begin{array}{l}4 \\
4 \\
\end{array}$ & traces & & \\
\hline 5 & 200 & $30,70^{\circ}$ & $100 \mathrm{~nm}$ & $\mathrm{~K}_{\text {comp }}$ & $\begin{array}{l}1.89 \\
1.87 \\
\end{array}$ & $\begin{array}{l}0.15 \\
0.16 \\
\end{array}$ & $\begin{array}{l}0.98 \\
1.02 \\
\end{array}$ & $\begin{array}{l}3.99 \\
3.92 \\
\end{array}$ & $\begin{array}{l}\text { traces } \\
\text { traces }\end{array}$ & traces & traces \\
\hline 6 & \begin{tabular}{|c|}
120 \\
$\&$ \\
300
\end{tabular} & $\begin{array}{c}30,8^{\circ} \\
\& \\
30,0^{\circ}\end{array}$ & $100 \mathrm{~nm}$ & $\mathbf{K}_{\text {comp }}$ & $\begin{array}{l}1.56 \\
1.67\end{array}$ & $\begin{array}{l}0.20 \\
0.17\end{array}$ & $\begin{array}{l}1.24 \\
1.16\end{array}$ & $\begin{array}{l}4 \\
4\end{array}$ & $\begin{array}{l}\text { traces } \\
\text { traces }\end{array}$ & & \\
\hline 7 & 200 & $10,30^{\circ}$ & $150 \mathrm{~nm}$ & $\mathrm{~K}$ ? & 1.72 & 0.21 & 1.05 & 4 & traces & & \\
\hline 8 & 200 & $30,15^{\circ}$ & & $\overline{\mathrm{K}_{\text {comp }}}$ & $\begin{array}{l}1.40 \\
1.46 \\
\end{array}$ & $\begin{array}{l}0.42 \\
0.38 \\
\end{array}$ & $\begin{array}{l}1.14 \\
1.13 \\
\end{array}$ & $\begin{array}{l}4 \\
4 \\
\end{array}$ & $\begin{array}{l}0.05 \\
0.03 \\
\end{array}$ & traces & \\
\hline 9 & 200 & $30,20^{\circ}$ & & $\mathrm{K}_{\text {comp }}$ & $\begin{array}{l}1.72 \\
1.45 \\
\end{array}$ & $\begin{array}{l}0.15 \\
0.18 \\
\end{array}$ & $\begin{array}{l}0.93 \\
0.92 \\
\end{array}$ & $\begin{array}{l}4.18 \\
4.34 \\
\end{array}$ & $\begin{array}{l}\text { traces } \\
\text { traces }\end{array}$ & traces & traces \\
\hline 10 & 120 & $30,72^{\circ}$ & & $\mathrm{K}_{\text {comp }}$ & $\begin{array}{l}1.60 \\
1.56 \\
\end{array}$ & $\begin{array}{l}0.28 \\
0.28 \\
\end{array}$ & $\begin{array}{l}1.12 \\
1.16 \\
\end{array}$ & $\begin{array}{l}4 \\
4 \\
\end{array}$ & traces & traces & \\
\hline 11 & 400 & $10,65^{\circ}$ & & $\mathrm{K}_{\text {theor }}$ & 1.70 & 0.18 & 0.91 & 4.21 & traces & & \\
\hline 12 & 200 & $30,20^{\circ}$ & & & & & & & traces & traces & traces \\
\hline
\end{tabular}

\section{Results.}

All results of the test and analysis conditions provided by the laboratories are gathered in tables I and II, for EDXS and EELS measurements respectively. A first informative way of surveying these results is to consider the average value and the dispersion of the measured compositions, 
with respect to the nominal reference values, for the three most used analytical modes - only one laboratory has achieved EELS measurements in the nanoprobe mode. Table III summarizes these data for the three elements $\mathrm{Mg}, \mathrm{Fe}, \mathrm{Si}$. Oxygen has been excluded from these average values, because most laboratories in EDXS have only given the stoichiometry value, being not capable of real measurements with an ultra-thin window detector.

Table II. - PEELS results and experimental parameters. Standard text corresponds to the results of standard mode analyses and italic text shows the results of nanoprobe analyses.

\begin{tabular}{|c|c|c|c|l|l|l|l|l|l|l|l|}
\hline Lab. & $\mathrm{kV}$ & $\begin{array}{c}\text { holder } \\
\text { temp. }\end{array}$ & $\begin{array}{c}\text { collection } \\
\text { angle }\end{array}$ & filament & $\mathrm{Mg}$ & $\mathrm{Fe}$ & $\mathrm{Si}$ & $\mathrm{O}$ & $\mathrm{Ni}$ & $\mathrm{M} \mathrm{n}$ & $\mathrm{Ca}$ \\
\hline 5 & 200 & $102 \mathrm{~K}$ & $3.5 \mathrm{mrad}$ & $\mathrm{LaB} 6$ & 1.90 & 0.20 & 1.07 & 3.83 & traces & & \\
\hline 6 & 300 & $300 \mathrm{~K}$ & $4 \mathrm{mrad}$ & LaB6 & $\begin{array}{l}2.00 \\
0.99\end{array}$ & $\begin{array}{l}0.11 \\
0.13\end{array}$ & $\begin{array}{l}1.02 \\
1.65\end{array}$ & $\begin{array}{l}3.87 \\
4.23\end{array}$ & & & \\
\hline 11 & 400 & $113 \mathrm{~K}$ & $5 \mathrm{mrad}$ & LaB6 & 1.67 & 0.16 & 1.05 & 4.11 & traces & & \\
\hline 12 & 100 & $300 \mathrm{~K}$ & $\begin{array}{l}15 \mathrm{and} \\
25 \mathrm{mrad}\end{array}$ & FEG & 1.90 & 0.2 & 1.3 & 4 & traces & & \\
\hline
\end{tabular}

Table III. - Summary of the data for $\mathrm{Mg}, \mathrm{Fe}$, Si: average values and dispersion of the measured compositions, with respect to the nominal reference values.

\begin{tabular}{|c|c|c|c|c|}
\hline & Nominal values & $\begin{array}{c}\text { EDXS in standard } \\
\text { mode }(11 \text { lab.) }\end{array}$ & $\begin{array}{c}\text { EDXS in nanoprobe } \\
\text { mode }(9 \text { lab. })\end{array}$ & $\begin{array}{c}\text { EELS in standard } \\
\text { mode }(4 \text { lab. })\end{array}$ \\
\hline $\mathrm{Mg}$ & $1.79 \pm 0.02$ & $1.66 \pm 0.15$ & $1.59 \pm 0.14$ & $1.86 \pm 0.12$ \\
\hline $\mathrm{Fe}$ & $0.200 \pm 0.007$ & $0.25 \pm 0.09$ & $0.24 \pm 0.07$ & $0.17 \pm 0.04$ \\
\hline $\mathrm{Si}$ & $1.00 \pm 0.01$ & $1.04 \pm 0.10$ & $1.10 \pm 0.12$ & $1.11 \pm 0.11$ \\
\hline
\end{tabular}

A more detailed observation of these data is to gather within diagrams the deviations obtained by the different laboratories - see figures 1 for the measured ratios $\mathrm{Mg} / \mathrm{Si}(1 \mathrm{a}), \mathrm{Fe} / \mathrm{Si}(1 \mathrm{~b}), \mathrm{O} / \mathrm{Si}$ (1c) in EDXS, and Mg/Si and O/Si (1d) in EELS.

\section{Discussion of the results and test specificity.}

4.1 GenERAL COMMENTS. - Concerning the major constituants ( $\mathrm{Si}, \mathrm{O}, \mathrm{Mg}, \mathrm{Fe}$ ), two general comments can be made concerning the results:

- the dispersion of the results is quite important,

- obvious problems in quantification have been $e_{\mathrm{L}}$ countered with the nanoprobe mode.

Before discussing the possible reasons and causes of such effects, more detailed considerations can be extracted from examination of the above tables and graphs:

- the nominal composition value generally falls within the errors on the measurements for all elements and all modes, except for $\mathrm{Mg}$ in the nanoprobe EDXS mode. 

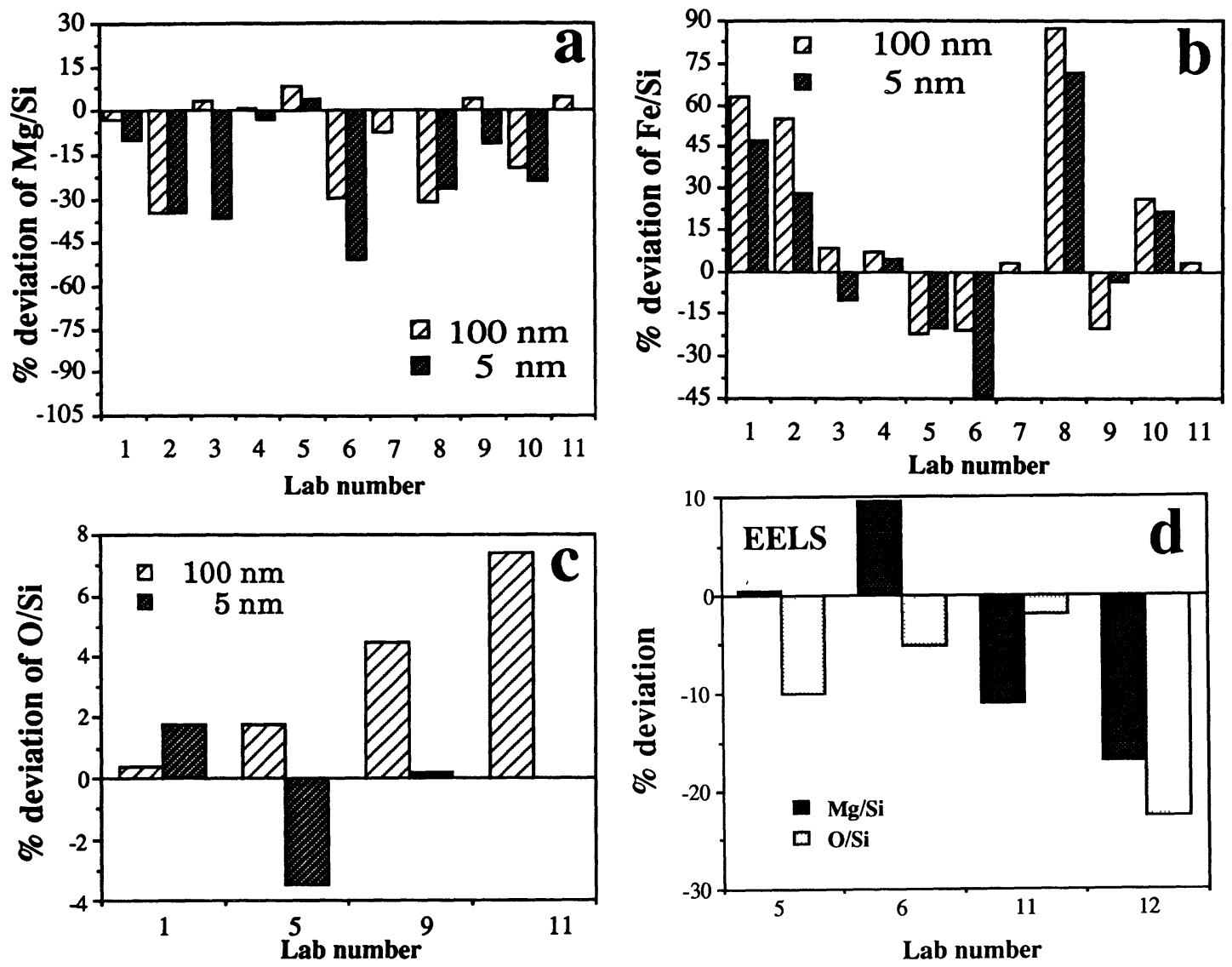

Fig. 1. - Histograms showing the percentage of deviation of both standard and nanoprobe EDXS and EELS data of the different laboratories from microprobe composition of San Carlos olivine. a) EDXS data percentage deviation of $\mathrm{Mg} / \mathrm{Si}$ ratio: $\left(\frac{(\mathrm{Mg} / \mathrm{Si})_{\text {measured }}-(\mathrm{Mg} / \mathrm{Si})_{\mu \text { probe }}}{(\mathrm{Mg} / \mathrm{Si})_{\mu \text { probe }}}\right)$, b) EDXS data percentage deviation of $\mathrm{Fe} / \mathrm{Si}$ ratio: $\left(\frac{(\mathrm{Fe} / \mathrm{Si})_{\text {measured }}-(\mathrm{Fe} / \mathrm{Si})_{\mu \text { probe }}}{(\mathrm{Fe} / \mathrm{Si})_{\mu \text { probe }}}\right)$, c) EDXS data percentage deviation of $\mathrm{O} / \mathrm{Si}$ ratio: $\left(\frac{(\mathrm{O} / \mathrm{Si})_{\text {measured }}-4}{4}\right)$, d) EELS data percentage deviations of $\mathrm{Mg} / \mathrm{Si}$ ratio: $\left(\frac{(\mathrm{Mg} / \mathrm{Si})_{\text {measured }}-(\mathrm{Mg} / \mathrm{Si})_{\mu \text { probe }}}{(\mathrm{Mg} / \mathrm{Si})_{\mu \text { probe }}}\right)$, and of $\mathrm{O} / \mathrm{Si} \mathrm{ratio:}\left(\frac{(\mathrm{O} / \mathrm{Si})_{\text {measured }}-4}{4}\right)$.

- however, in EDXS, Mg is underestimated and Fe overestimated with respect to $\mathrm{Si}$, while it is reserved for EELS analysis.

- when comparing the standard and the nanoprobe EDXS modes, the measured Mg concentration is smaller in the latter case, it is the reverse for $\mathrm{Si}$, and Fe does not seem to be very sensitive upon the irradiation conditions.

The presence of minor elements has been diversely reported through EDXS results - see table I -. All laboratories have detected the presence of $\mathrm{Ni}$ in the standard mode. The failure of Mn detection by more than one third of the laboratories is likely due to the weaker detection effciciency of their detector (lower collection solid-angle for $10 \mathrm{~mm}^{2}$ size). A promising observation 
is that $25 \%$ of the test participants have detected the presence of Ca with an atomic concentration lower than $0.03 \%$ - see figure 2 . Of course, in the nanoprobe mode, the sensitivity of minor elements detection is greatly reduced. However, $\mathrm{Ni}$ and even $\mathrm{Mn}$ have been detected in some cases.

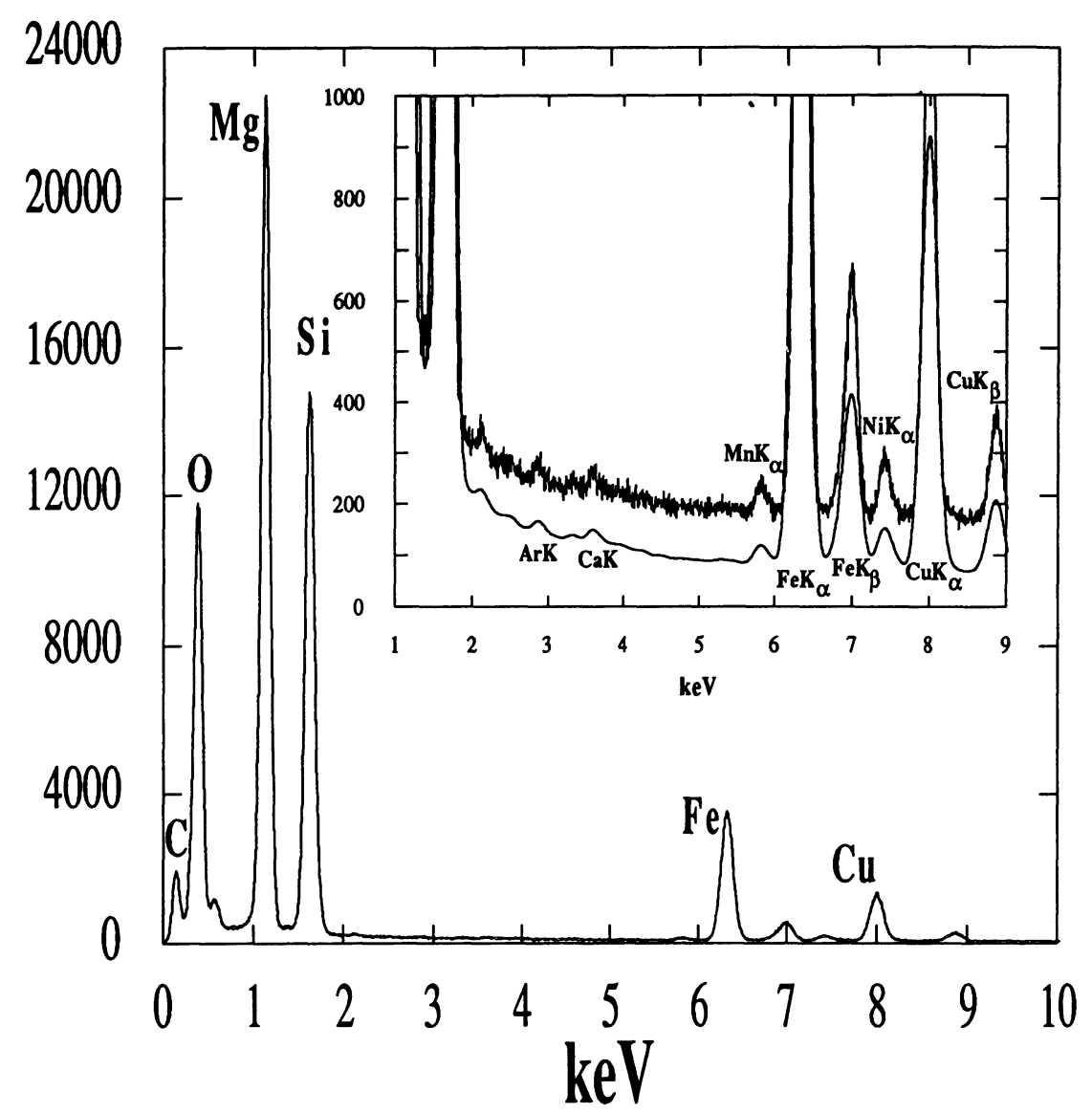

Fig. 2. - San Carlos olivine X-ray spectra $(0.00-10.00 \mathrm{keV})$ collected in standard mode $(100 \mathrm{~nm})$ with a time collection of $1000 \mathrm{~s}$. A detail of the higher energy part of the spectrum is enlarged in order to show the detection of minor $\mathrm{Ni}, \mathrm{Mn}$ and $\mathrm{Ca}$ elements. The smoothed spectrum, is shown below the raw spectrum in order to underline the presence of this element. Notice that the $\mathrm{Ar}_{\mathrm{K} \alpha}$ peak is due to implantation of $\mathrm{Ar}$ atoms during ionic thining of the sample.

As for EELS experiments, two laboratories have detected trace elements using the second difference acquisition procedure, see figure 3. They have reported Ni but with a slightly lower concentration than expected $(<160 \mathrm{ppm})$. $\mathrm{Mn}$ and $\mathrm{Ca}$ have not been detected. The improved detection of trace elements by EDXS is due to high signal to background ratio on high energy $\mathrm{K}$-lines while only L edges with weak signal to background ratio are used in EELS.

All these observed behaviours have different origins. Some of them are related to the experiment itself and in particular to the beam sensitivity of the specimen. Others are due to data acquisition and processing, which are very different for EDXS and EELS analysis. 


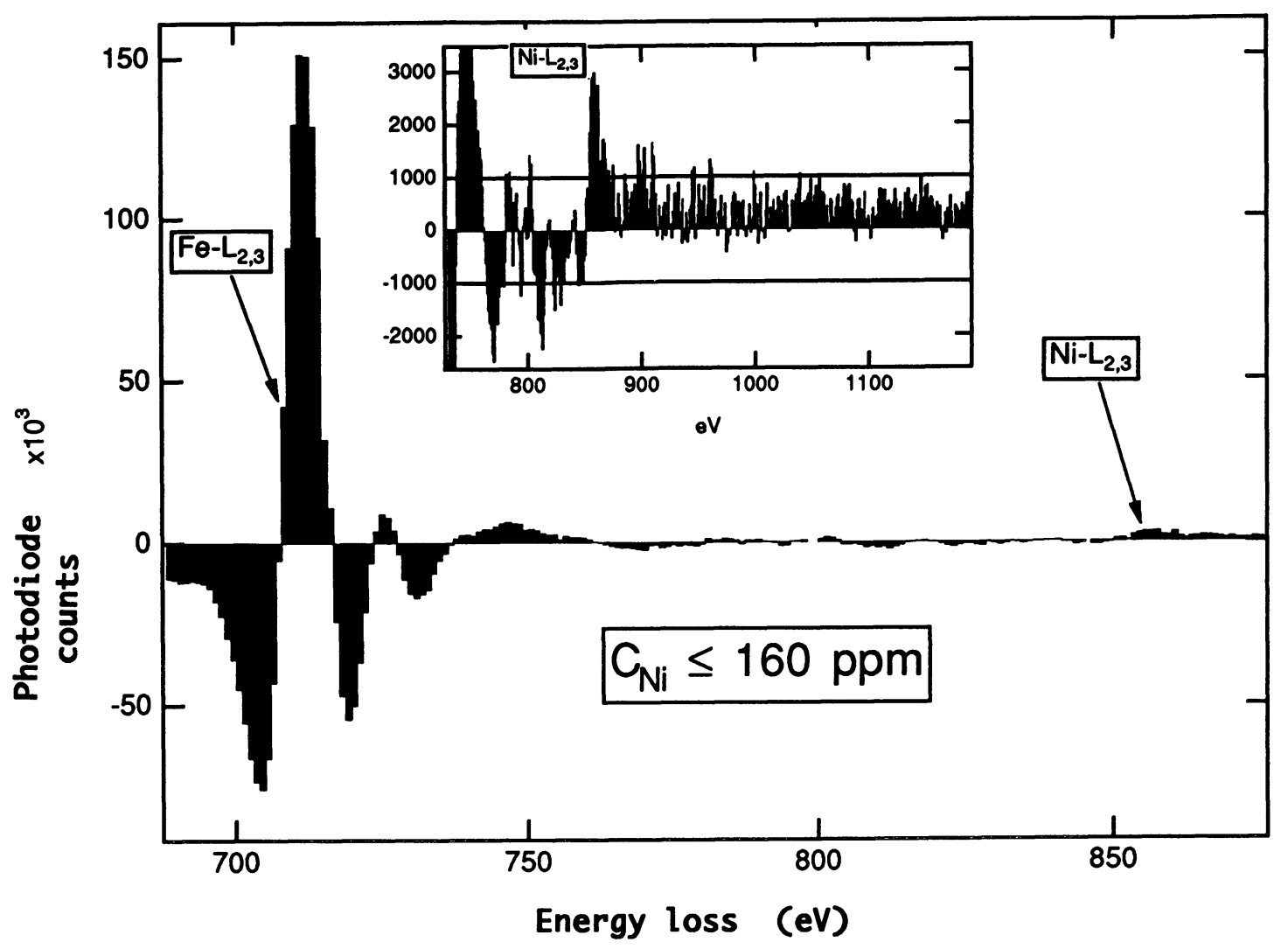

Fig. 3. - Detection of Ni traces from the second difference mode in PEELS.

\subsection{EDXS ANALYSIS.}

4.2.1 Absorption correction. - Only four laboratories have considered and performed absorption correction. As a major consequence, it modifies the ratio between the Fe- $\mathrm{K}$ line which is moderately absorbed and the $\mathrm{Si}-\mathrm{K}$ line which is heavily absorbed. The positive average deviation of $+14.6 \%$ for the Fe/Si ratio (for all measurements displayed in Fig. 1b) suggests indeed that the overestimation of the Fe content is largely due to the absence of any absorption correction. As a matter of fact, the deviation falls to $1.2 \%$ for the four laboratories which have performed absorption correction, by setting arbitrarily the thin foil thickness to 100 or $150 \mathrm{~nm}$. For olivine mineral with a density close to $3.2 \mathrm{~g} / \mathrm{cm}^{2}$, the TEM thin section remains transparent to $200 \mathrm{kV}$ electrons for thicknesses up to $400-500 \mathrm{~nm}$, notably greater than what is currently observed for metallurgical specimens. It can lead the observer to analyse specimen areas thicker than normally accepted as "thin" films. Moreover, when concerned with the quantitative analysis of very light element such as oxygen, the deviations may be critical if no absorption correction is applied.

In order to evaluate a critical thickness, the calculation of the absorption factor can be applied to San Carlos olivine from the expression proposed by Cliff and Lorimer [1] and from the values of the mass absorption coefficients given in [2-3]. We find that the $\mathrm{K}_{\mathrm{Fe} / \mathrm{Si}}$ factor should decrease by $3.6 \%$ and the $\mathrm{K}_{\mathrm{O} / \mathrm{Si}}$ factor increase by $8.4 \%$ for a sample thickness of $100 \mathrm{~nm}$ and a take-off angle of $30^{\circ}$. If the take-off angle is greater, for instance $75^{\circ}$, the same absorption correction will 
apply for a sample thickness of about $200 \mathrm{~nm}$.

The absorption correction described here is relatively simple and does not consider the different geometrical conditions of detectors used by the laboratories which participated to the test; it may affect notably the absorption corrections [4]. However, it underlines clearly the necessity to realize such corrections for olivine in order to obtain the true composition of the sample or if possible to use an extrapolation method as proposed by Horita et al. [5] and Van Cappellen [6].

4.2.2 $k$-factors calibration - Only one laboratory has used $k$-factors deduced from calibration on a test specimen (laboratory ${ }^{\circ} 4$ calibrates the $k$-factors with $\mathrm{FeSi}_{2}$ and $\mathrm{Mg}_{2} \mathrm{SiO}_{4}$ standards) and three of the four laboratories which have realized oxygen measurement have performed this type of calibration for oxygen only (laboratories $n^{\circ} 1,5,9$ ). Most laboratories have introduced the $k$-factors proposed by the company which has supplied the detector; a few have used theoretical $k$-factors calculated for their specific detector. It is not surprising that the laboratory $\mathrm{n}^{\circ} 4$ got the best results. The results of the oxygen measurements (Fig. 1c) performed by four laboratories are indeed very promising; the deviation from the nominal value is very low, especially for the two laboratories ( $\mathrm{n}^{\circ} 1$ and 5$)$ which have performed both calibration with standards and absorption corrections.

It is obvious that the people who have initiated quantitative measurements of low $\mathrm{Z}$ elements with ultrathin window detectors have become more concerned with all sources of errors in data processing.

4.3 EELS ANALYSIS. - EELS technique is quite sensitive to the spectrum acquisition conditions and to the data processing schemes. It is therefore motivating to check that the dispersion of quantitative results can be a-posteriori accounted for by a critical evaluation of those parameters. The four laboratories have much in common; they have all used the same PEELS Gatan piece of equipment, they have all used the same principle for quantification, i.e. background modelization and extrapolation, they have all used the same programs sigmak et sigmal [7] for the calculation of cross-sections. The major differences concern the EM instrumental parameters (primary voltage, angle of collection) and the local specimen parameters (thickness).

4.3.1 Quantification of major elements - The following edges have been used: $\mathrm{O}-\mathrm{K}$ at $532 \mathrm{eV}$, Fe- $\mathrm{L}_{23}$ at $708 \mathrm{eV}, \mathrm{Mg}-\mathrm{K}$ at $1305 \mathrm{eV}, \mathrm{Si}-\mathrm{K}$ at $1839 \mathrm{eV}$. They extend over more than $1300 \mathrm{eV}$. Since the dispersion generally used for the spectrum acquisition is $1 \mathrm{eV} /$ channel, data have been recorded in more than one spectrum and scaled afterwards. The standard quantification procedure [7] with modelization of the pre-edge spectrum with a power-law function $\left(A . E^{-R}\right)$ can be straightforwardly used over this domain range. Moreover, there is no real problem of edge overlap, because the used edges are separated by more than $100 \mathrm{eV}$. It could not have been the case, if the $\mathrm{Mg}-\mathrm{L}_{23}$ $(51 \mathrm{eV})$ and Si- $\mathrm{L}_{23}($ at $104 \mathrm{eV})$ had been used. One laboratory $\left(\mathrm{n}^{\circ} 5\right)$ has actually tried to quantify Si using this low energy edge but has got unsatisfactory results.

Owing to the small number of participating laboratories, it is difficult to conclude about the dispersion of the PEELS results compared to EDXS. Furthermore, only EDXS and PEELS comparison of data coming from the same microscope (laboratories $n^{\circ} 5,6,11$ ) could eventually give reliable informations. In this case, the dispersion is larger for the PEELS results. However, looking at the table II, we can note that the greater deviation in Si content, compared to reference composition, is observed for the microscope with the lower accelerating voltage for which the $\mathrm{Si}$ $\mathrm{K}$ edge lies at the end of its accessible energy range. It demonstrates the interest of using higher primary voltage instruments (which offer increased peak to background ratio values) to perform quantitative analysis with edges in the $1-3 \mathrm{kV}$ range. The other instrumental parameters are the accuracy in the measurement of the collection angle $(\beta)$ and the integration window $(\Delta)$ for signal 
measurement and cross section calculations. As a matter of fact, the collection angles are similar for the three laboratories $\left(n^{\circ} 5,6,11\right)$ performing EELS with a TEM microscope and are nearly maximum by using a short camera length $(10-20 \mathrm{~cm})$ in order to record the highest signal. Angular effects associated to the spectrometer acceptance are therefore limited for these three TEMs. They do not seem to induce strong variations for the dedicated STEM instrument which accepts larger angles of collection. The integration window width used by the four laboratories varies from $50 \mathrm{eV}$ to $130 \mathrm{eV}$ and no detailed investigation of the influence of this factor has been achieved by any experimentalist. The general feeling is that it does not induce noticeable deviations with respect to the nominal value, as long as a typical $100 \mathrm{eV}$ width is used for such non-overlapping edges.

Finally, the most critical parameter is the specimen thickness. One knows that noticeable variations in measured compositions happen when the thickness is of the order or greater than one mean free path for inelastic scattering, i.e. typically $100 \mathrm{~nm}$ at $100 \mathrm{kV}, 200 \mathrm{~nm}$ at $300 \mathrm{kV}$. To reduce this effect, deconvolution techniques are available to eliminate multiple events involving plasmon losses superposed on the characteristic edges. It must be recognized that no participant to the round robin test has followed a completely satisfactory data acquisition and processing scheme, including the recording of a non-saturated low loss spectrum for the estimation of the local thickness. The only general rule has been to perform EELS measurements on sufficiently thin areas, which on the other hand are more sensitive to beam-induced transformation, as it can easily be demonstrated in nanoprobe studies.

4.3.2 ELNES fine structures - When compared to EDXS analysis, EELS provides extrainformation on the electronic state, local structure, environment of the excited site through the spectral intensity distribution over the first $50 \mathrm{eV}$ above the ionization edge. All participants have recorded the edge shapes for the major elements with an energy resolution between 0.7 and 2 or $3 \mathrm{eV}$. No important variations have been noticed apart the smoothing effect associated to the resolution functions different from one instrument to another. Although these fine structures were not typically within the scope of the present round-robin experiment, the general results were as follows:

- The Si-K edge (Fig. 4a) exhibits a narrow line at the edge characteristic of Si-O bonds. The asymmetrical shape of this line corresponds generally to the tetrahedral site [8], which is therefore consistent with the forsterite mineral $\left(\mathrm{Mg}_{2} \mathrm{SiO}_{4}\right)$.

- One of the best O-K edges is shown in figure $4 \mathrm{~b}$. It differs from the $\mathrm{SiO}_{2}$ profile by the splitting by $2.7 \mathrm{eV}$ of the intense peak at threshold which suggests that oxygen are located in two different types of site (see also [9]).

- The Fe- $\mathrm{L}_{23}$ edge displays the characteristic white line doublet, the ratio of which is known to be dependent on the oxidation state [10]. The values measured by two distinct participants using different methods for estimating the intensity of the white lines, range between 3.5 and 4.5. By comparison with the values measured on standards, it suggests a divalent iron ion.

4.4 BEAM INDUCED SPECIMEN MODIFICATION. - Minerals, and silicates in particular, are sensitive to electron irradiation, mostly through radiolysis mechanisms [11-13]. In olivine, the beam damage induces a loss of mass which preferentially affects light elements: $\mathrm{O}, \mathrm{Mg} . . .[14,15]$. The mass loss depends on both the dose rate and the total dose received by the sample. However, a threshold $J_{\mathrm{c}}$ for the current density exists for a given element in a given silicate structure at a particular voltage, below which no loss occurs. It corresponds to a balance between forward damage processes and reversible events. Typical values for $J_{c}$ are in the $10^{5}-10^{6} \mathrm{~A} \cdot \mathrm{m}^{2}$ range.

This phenomenon can substantially alter the characteristic X-ray as well as EELS intensity ratio resulting from analysis performed above this threshold current density. Figure 5 shows an 

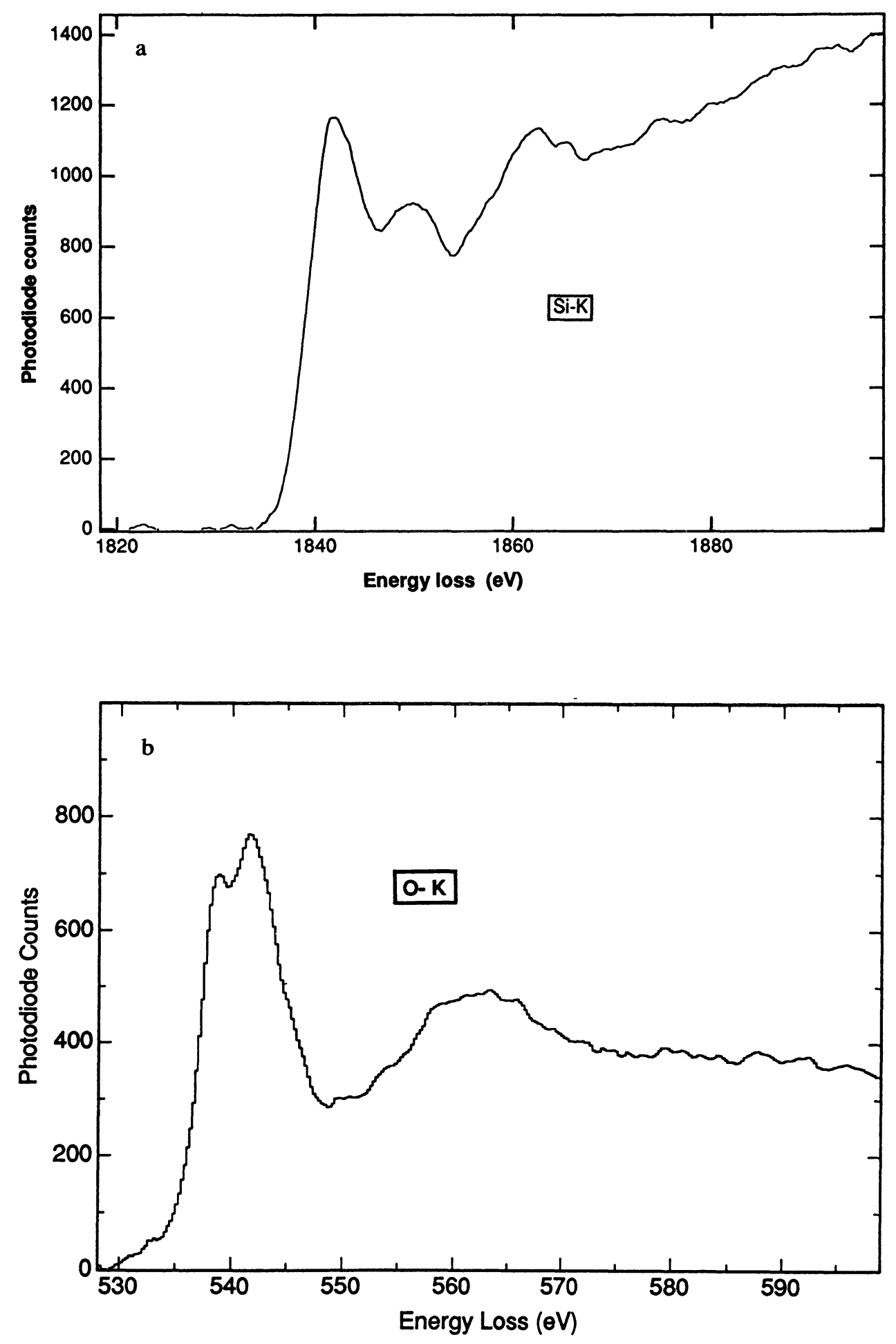

Fig. 4. - ELNES fine structures on the a) Si-K edge and b) O-K edge. 
example of X-ray spectra obtained in the standard mode $(\cong 100 \mathrm{~nm}$ probe). The storage of spectra acquired with increasing time periods $(10 \mathrm{~s}, 20 \mathrm{~s}, 40 \mathrm{~s}, 60 \mathrm{~s}, 160 \mathrm{~s}, 320 \mathrm{~s}$ and $640 \mathrm{~s})$ clearly reveals that the $\mathrm{O} / \mathrm{Si}$ and $\mathrm{Mg} / \mathrm{Si}$ ratios decrease noticeably with the acquisition time.

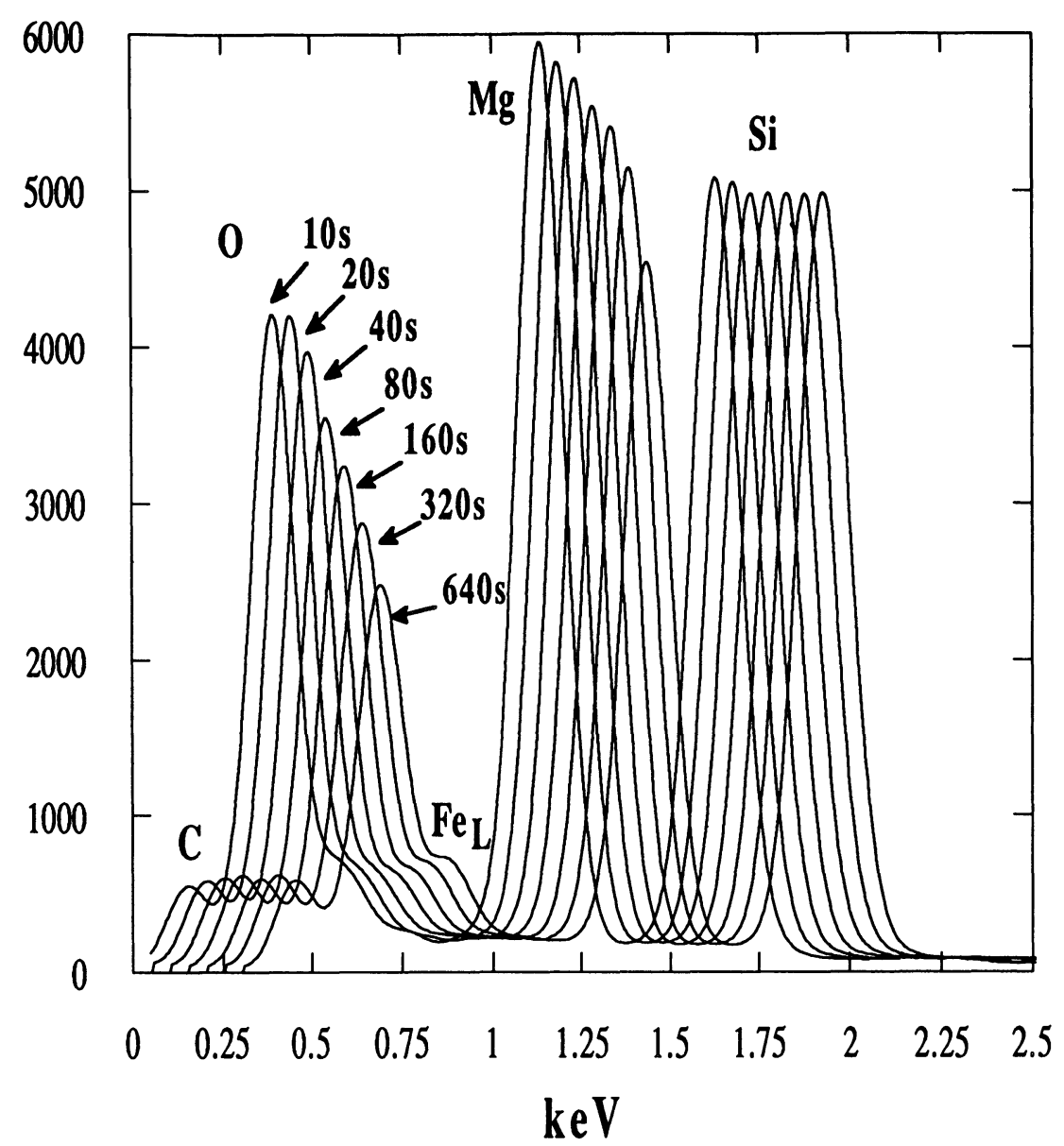

Fig. 5. - Cumulative low energy X-ray spectra $(0.00-2.50 \mathrm{keV})$ obtained after $10 \mathrm{~s}, 20 \mathrm{~s}, 40 \mathrm{~s}, 80 \mathrm{~s}, 160 \mathrm{~s}$, $320 \mathrm{~s}$ and $640 \mathrm{~s}$ of analysis on the same area. The spectra have undergone a gaussian smooth and have been rescaled to a common intensity for the $\mathrm{Si} \mathrm{X}$-ray peaks. Each spectrum has been shifted of $50 \mathrm{eV}$ relative to the previous one for the commodity of presentation. The $C_{K \alpha}$ peak is quite constant which means that contamination remains very small all along the analysis and thus does not affect it.

Considering again the quantitative analysis of major elements, most participants have found a $\mathrm{Mg} / \mathrm{Si}$ ratio value well below the nominal one, as shown in figure 1a. This underestimation is therefore likely due to a $\mathrm{Mg}$ loss during analysis. The average deviation (sum of the deviations of all data divided by the number of data) in the standard mode $\delta_{\text {stand }}$ is equal to $-9.6 \%$ in the EDXS case and $-4.8 \%$ in the PEELS one.

The average deviation still increases for the nanoprobe analysis $\left(\delta_{\text {nano }}=-21.6 \%\right.$ in EDXS mode and $\delta_{\text {nano }}=-60 \%$ in PEELS mode). The drastic increase of the underestimation of the 
$\mathrm{Mg}$ content with the nanoprobe mode must be attributed to the important increase of the current density received by the sample with this mode thus increasing the $\mathrm{Mg}$ loss during the analyses. One-third of the microscopists did not notice that some $\mathrm{Mg}$ was lost during their analysis. Another third were not disturbed by the phenomenon because they worked at low current intensity and/or they reduced the effect of Mg-escape by working with a nitrogen low-temperature sample holder. The last third effectively observed the Mg-loss during their analyses; however, only half of them were able to collect their spectra for a beam intensity below the critical threshold current density which initiates the loss.

\section{Conclusions and perspectives.}

This first round robin test has permitted to promote an enthousiastic new kind of communication and exchange between microscopists sharing common techniques and problems. The present evaluation is intended not to assess the real potential of the techniques by themselves, but to evaluate the way that they are handled by a group of operators with distinct instruments and different data processing approaches. It has involved two levels of participation: the first one was to perform the required measurements individually, the second one has been to gather all participants in order to scrutinize the results, to identify the sources of disagreement and to propose new ways for improving and unifying the general quality of the results.

This collaborative reflexion has led to the following conclusions:

- no drastic difference has been evidenced between the two techniques EDXS and EELS for quantifying major elements. Nevertheless, improvements should be acquired through the following routes:

- generalization of a rigorous procedure for absorption correction in EDXS,

- introduction of the determination of $\mathrm{k}$ factors from standards in EDXS,

- development of novel modelization techniques for EELS, including the utilisation of spectra from standards [16].

- EDXS has revealed to be superior to EELS for the detection of minor elements, with the presently used data processing techniques. As a matter of fact, all laboratories have detected $\mathrm{Ni}$ with EDXS but only two with EELS, and Mn and Ca could only be detected with EDXS.

- even in the standard mode, one of the major difficulties for the analysis of this type of specimen lies in the preferential loss of one element or another under the primary electron beam. Evidently, this effect is the more disturbing as one looks for high spatial resolution in the nanoprobe mode. Possible ways to circumvent this difficulty have been mentioned such as a more general use of temperature specimen holders.

Finally, in agreement with all participants, two fundamental aspects of data processing, i.e. thickness effect and use of standards have been selected to be the subject of the next 1993 round robin test for the Ile-de-France TEM Network.

\section{Acknowledgements.}

J. Ingrin has kindly provided the San Carlos olivine thin sections used for the test. D. Bouchet, C. Colliex, G. Hug., D. Imhoff and J. Ingrin have elaborated the present critical evaluation of all the measurements. P. Bertrand has provided access to the microprobe of Paris VI, M. Rommeluere and C. Bahezre to the microprobe of CNRS - Meudon. 


\section{References}

[1] ZALUZEC N.J., Introduction to Analytical Electron Microscopy, J.J. Hren, J.I. Goldstein and D.C. Joy Eds. (Plenum, New York, 1979) 121.

[2] HEINRICH K.F.J., The electron microprobe, T.D. Mc Kinley, K.F.J. Heinrich and D.B. Wittry Eds. (J. Wiley, New York, 1964) 296.

[3] HENKE L.H. and EBISU E.S., Adv. X-ray anal. 17 (1974) 150.

[4] ZREIBA N.A. and KeLlY T.F., Ultramicrosc. 33 (1990) 187.

[5] HORITA Z., SANO T. and NEMOTO M., Ultramicrosc. 21 (1987) 271.

[6] VAN CAPPELlEn E., Microsc. Microanal. Microstr. 1 (1990) 1.

[7] EGERTON R.F. (Plenum Press, New York, 1986).

[8] TAFTO J. and ZHU J., Ultramicrosc. 9 (1982) 9.

[9] P'AYNE R.S., CRICK R.A., MCCOMB D.W., Emag (1991).

[10] Colliex C., Manoubi T., Ortiz C., Phys. Rev. B 44 (1991) 11402.

[11] HoBBS L.W., Introduction to Analytical Electron Microscopy, J.J. Hren, J.I. Goldstein and D.C. Joy Eds. (Plenum, New York, 1979) 437.

[12] HoBBS L.W., Proc. $25^{\text {th }}$ Scottish Univ. Summer School in Physics (1984) 399.

[13] CATER E. and BUSECK P.R., Ultramicrosc. 17 (1985) 241.

[14] ChampNess P.E. and DEVENISH R.W., Proc. EUREM 92 Congress, Granada (Spain) 2 (1992) 541.

[15] ChampNess P.E. and DeVEniSh R.W., Trans. Roy. Microsc. Soc. 1 (1990) 177.

[16] LEAPMAN R.D., Transmission Electron Energy Loss Spectrometry in Materials Science, M.M. Disko, C.C. Ahn and B. Fultz Eds., T.M.S. (1992) 47. 